\title{
The Role of the Endocannabinoid System in the Gynaecological Malignancy
}

\author{
Flavio Grauso ${ }^{1}$, Raffaele Autiero², Giuseppe R. Lannino ${ }^{3}$, Brunella Zizolfi ${ }^{4}$, Ciro Perone ${ }^{5}$ and \\ Enrico M. Messalli 6,* \\ 1 Advanced Endoscopic Gynaecological Surgery Center, Endogyn Unit, Sanatrix Clinic, Naples, \\ Italy; flaviograuso@gmail.com; \\ 2 University of Campania Luigi Vanvitelli; raffaele.autiero@libero.it ; \\ 3 Advanced Endoscopic Gynaecological Surgery Center, Endogyn Unit, Sanatrix Clinic, Naples; \\ Italy; g.r.lannino@gmail.com ; \\ 4 Advanced Endoscopic Gynaecological Surgery Center, Endogyn Unit, Sanatrix Clinic, Naples; \\ Italy; brunellazizolfi@hotmail.it ; \\ 5 Advanced Endoscopic Gynaecological Surgery Center, Endogyn Unit, Sanatrix Clinic, Naples; \\ Italy; peroneciro@gmail.com ; \\ 6 University of Campania Luigi Vanvitelli; enricom.messalli@unicampania.it \\ * Correspondence: enricom.messalli@unicampania.it; Tel.: +39-081-5665601
}

\begin{abstract}
Background: The endocannabinoid system (ECS) is a very heterogeneous array consisting of many proteins like ligands, enzymes and receptors synthetized in various tissues and immunity cells. The main endogenous ligands are unsaturated fatty acid derivatives like anandamide(AEA), 2-arachidonoylglycerol(2-AG), but many others are under study. Endocannabinoids are involved in both physiological and pathological conditions. ECS plays an important role in the regulation of main processes which lead to cancer and also in sex steroid hormone-related cancers.
\end{abstract}

Methods: With focus on gynaecological cancers, main papers and review articles, up to April 2018, on the role of the ECS, were acquired by PubMed searches using the search terms: 'cancer', 'cannabinoid', 'endocannabinoid', 'gynaecology' and 'malignancy'.

Results: The review of recent literature data showed the involvement of the endocannabinoid system in numerous physiological and pathological conditions of the female genital tract up to the development of gynaecological malignancy as cervical, endometrial and ovarian cancer.

Conclusions: The endocannabinoid system has an important role in antitumor actions involving different signalling receptor and receptor-independent pathways. It represents an exciting challenge to researchers for its potential use in diagnosis and treatment of all gynaecological malignancies.

Keywords: endocannabinoid system; gynaecological cancers; endometrial cancer; cervical cancer; ovarian cancer, CB1R; CB2R; FAAH;

\section{Introduction}


The endocannabinoid system (ECS) is made up of many proteins like ligands, enzymes involved in their synthesis and their degradation, and receptors [1]. The main endogenous ligands are unsaturated fatty acid derivatives like anandamide(AEA), 2-arachidonoylglycerol(2-AG), 2-arachidonoylglycerol ethere, o-arachidonoyl-ethanolamine, and $\mathrm{N}$-arachidonoyl-dopamine (NADA) [2, 3, 4, 5]. These substances are synthetized in various tissues and immunity cells by specific synthetases as [N-acylphosphatidylethanolamine-hydrolyzing phospholipase (NAPE-PLD) for AEA and its congeners and diacylglycerollipase (DAGL) for 2-AG] [4]. The main enzyme involved in degradation of these substances is fatty acid amine hydrolase (FAAH) which degrades AEA in arachidonic acid and ethanolamine [6]. Therefore NAPE-PLD and FAAH are the main regulators of the concentration of AEA in target tissues and they are responsible of the so-called anandamide tone [7]. The synthesis of endocannabinoids, in particular AEA and 2-AG, is triggered by the increase of intracellular calcium level [8] and their precursors are phospholipids of cellular membrane. As for receptors, there are two g-protein coupled receptors involved in this system of signaling, CB1R and CB2R. CB1R is the main receptor in central nervous [9] system but it is also represented in peripheral tissues such as adrenal gland, ovaries, uterus, testis, prostate [10] and placenta [11]. CB2R is instead less represented in central nervous system, except for extreme stress conditions, whereas it has been found in immune-based tissues [12] such as spleen, tonsils, thymus, bone marrow, B-cells, natural killer cells, monocytes, polymorphic mononuclear cells, neutrophils and T8- and T4-postive cells and in the 1st trimester trophoblast [13]. Recent studies highlighted other cannabinoid putative receptors and in particular three G-protein coupled receptors have been related to ECS. They are GPR55, GPR119 [14,15] and GPR18 [16]. GPR55 has been identified in human reproductive tract and its ligands are three endocannabinoids, 2-arachidonoylglycerol $\mathrm{N}$-palmitoylethanolamide (PEA) and (2-AG), lysophosphatidyl-inositol [14]. GPR55 is involved in the development of human squamous skin cancer as its concentration increase in this pathology [17]. Another receptor involved in biological effects of endocannabinoids is a ligand-gated, $\mathrm{Ca} 2+$ permeable ion channel, the transient potential vanilloid receptor 1 (TRPV1) [15] that has a ubiquitous distribution [18]. The ligands of this receptor are N-Arachidonoylethanolamide, anandamide (AEA), and $\mathrm{N}$-arachidonoyldopamine (NADA), and therefore they can be included in a class of molecules called endovanilloides [18]. Other potential receptors are the peroxisome proliferator-activated receptors (PPARs) which are activated by endocannabinoids both in physiological and pathological situations [19]. 
Endocannabinoids are involved in many physiological and pathological conditions such as metabolic syndrome [20], chronic inflammation like inflammatory bowel disease [21, 22, 23], immunomodulation [24], various neurophysiological effects $[12,25]$ and cancer related pain [26, 27]. ECS plays an important role in the regulation of main processes which lead to cancer [ 28, 29,30,31,32] and there is an interesting relation with sex steroid hormone-related cancers [33,34]. An important effect of ECS is the regulation of cellular death. The activation of CB1R in response to environmental stimuli, regulate cell proliferation, differentiation and death thanks to the modulation of the balance among ERK, JNK and p38 MAPK activities [35]. Endocannabinoids can induce apoptosis through TRPVI receptor whose ligand is AEA. Through this interaction, AEA mediates cellular death in rat and human neurons [36,37], lymphoma cells [37] and cytotrophoblasts [38]. In general, ligands of cannabinoid receptors induce apoptosis inhibiting mitochondrial activity since they increase mitochondrial hydrogen peroxide production and decrease the consumption of oxygen and the mitochondrial membrane potential [39]. Another important effect of ECS is the inhibition of cancer cells invasion. These cells use metalloproteinases (MMP-9 and MMP-2) to degrade major basement membrane components, such as laminin, collagen and nidogens [40]. ECS indirectly downregulates the expression and the activity of MMP-2 through stimulation of TIMP-I that is an inhibitor of the metalloproteinase itself [41].

Endocannabinoids are also thought to be involved in the inhibition of neoangiogenesis decreasing the production of pro-angiogenic factors and/or by directly modulating endothelial cells [42] and decreasing the expression of VEGF and VEGF-R [43,44].

\section{Methods}

Main papers and review articles, up to April 2018, on the role of the ECS in cancer, with focus on gynaecological cancers, were acquired by PubMed searches using the search terms: 'cancer', 'cannabinoid', 'endocannabinoid', 'gynaecology' and 'malignancy'. Non-English manuscripts were discarded. Furthermore, reference lists of the obtained articles were scanned to identify additional relevant studies.

\section{Results}

\section{The Endocannabinoid system and gynaecologic Cancer}

Recent literature data showed the involvement of the endocannabinoid system in numerous physiological and pathological processes of the female genital tract [45, 
$46,47,48,49,50,51,52,53]$ It is not surprising that a dysregulation of the ECS might be involved in the development of gynaecological malignancy $[54,55,56]$.

\subsection{The endocannabinoid System ad Endometrial Cancer}

Different studies confirmed the presence of some components of the ECS in the uterus and have assessed their function. AEA has been related to decidualization, implantation and menstruation $[57,58,53]$. CB1R is mostly present in glandular epithelium and its expression increases in secretory phase [51, 52]. CB2R is expressed in glands and stroma [51], NAPE-PLD is expressed in the early proliferative phase of menstrual cycle [51] and FAAH is mainly expressed in stroma [51]. Regarding ECS, the most important marker as for endometrial carcinoma is $\mathrm{CB} 2 \mathrm{R}$ since it is mostly expressed in endometrial cancer biopsies and it results weakly present in normal endometrial tissue [59]. Other studies confirmed also that AEA levels are increased in cancer tissues [59,60]. CB2R probably plays a key role in the regulation of growth and death of cancer cells [61] and its pathway is altered in endometrial cancer [59]. In this type of cancer there is the elevation of the levels of CB2R and 2-AG probably due to the imbalance of estrogen/progesterone ratio [59]. A recent study on a cellular line of endometrial cancer (AN3CA) showed that $\mathrm{CB} 2 \mathrm{R}$ has a potential role in the control of cancer cells growth through the regulation of mitochondrial function and their apoptosis [59]. In the last few years a new kind of research called metabolomics [62] has been used in cancer research. This discipline examines the change of metabolic processes in cancer cells and compares the metabolism of these cells with normal cells of the same tissues to understand physiopathologic processes involved in cancer progression and to find new biomarkers potentially useful to discover new therapies [63, 64]. Furthermore, metabolomics studies demonstrated that there are differences in cellular metabolism between myometrial invasion front and non-invasive endometrial cancer cells. In fact, about invasive front there is an increased expression of endocannabinoid-like metabolites like stearamide and this confirm the potential involvement of ECS in tumoral invasion [65]. A recent study showed that the ECS maybe act as antagonist of the estrogen and in general, it could contrast increasing level of sex hormones playing a protective role in the development of hormones related cancers [66]. Another study analyzed the effect of ECS and phytocannabinoids (cannabidiolo, CBD), on cell viability in two endometrial cancer cell lines (Ishikawa cells and Hec50co). This study made clear that ECS and cannabidiol negatively influenced cancer cells viability at concentration superior than $5 \mu \mathrm{M}$ by increasing levels of caspase $-3 /-7$, cleaved PARP and reactive oxygen species generation. These data suggested apoptosis as the main mechanism involved. This effect is obtained through the stimulation of TRPV1 that leads to an increase of intracellular calcium level [67]. According to all these considerations it is clear that ECS plays an active role in physiopathology of endometrial cancer and 
it is mandatory to go ahead with scientific research in order to find new potential pharmacological target useful in the care of this cancer.

\subsection{The Endocannabinoid System and Cervical Cancer}

RT-PCR and Western blot analyses have confirmed the presence of CB1, CB2 and TRPV1 receptors in different cervical cancer cell lines [68]. The effect of AEA in cervical cancer has been examined in three cellular lines, that are Caski, HeLa and CC299. AEA determines apoptosis of cancer cells through a mechanism that is not mediated by CB1R and CB2R since their selective antagonists have demonstrated a synergic effect with AEA. [68]. On the other hand, the selective antagonist of TRPVIR (capsazepina) has been observed to have a protective effect against the action of AEA. For this reason, CB1R and CB2R protect cervical cancer cells against the effect of AEA and on the contrary the activation of TRPVI is involved with AEA in cellular death [68]. Another molecule involved in the stimulation of apoptosis in cervical cancer cells is Methanandamide (MA) that is a FAAH-resistant endocannabinoid analogue. MA stimulates apoptosis through the activation of COX-2 by a ceramide-dependent pathway [69]. Furthermore, MA is involved in the inhibition of cancer cell's invasion with a time and concentration dependent mechanism which determines the increase of the expression of TIMP-I [70].

\subsection{The Endocannabinoid System and Ovarian Cancer}

CB1R, CB2R, Fatty Acid Amide Hydrolase (FAAH) and $\mathrm{N}$-acyclphosphatidylethanolamine-phospholipase $\mathrm{D}$ (NAPE-PLD) immunohistochemical examination of normal human ovaries showed a presence and widely expression of the endocannabinoid system in the ovarian medulla and cortex. Furthermore, evident data suggested that anandamide is produced in the ovary and it is under hormonal control playing a role in folliculogenesis, preovulatory follicle maturation, oocyte maturation and ovulation [45].

The demonstration of CB1R and FAAH expression primarily in the Ovarian Surface Epithelium (OSE) was intriguing. The historical belief that OSE was the main source of ovarian cancer led to the assessment of the ECS expression in this tumor [71].

Functional proteomic analysis of (aggressive and non-aggressive) ovarian cancer data demonstrated that aggressive cancer cells display highly elevated monoacylglycerol hydrolytic activity and most of this activity originates from the Monoacylglycerol lipase (MAGL) enzyme [56], which degrades 2-AG. MAGL is highly expressed in aggressive human ovarian cancer cells, where it regulates a 
fatty acid network enriched in oncogenic signaling lipids that promotes migration, invasion, survival, and in vivo tumor growth. Overexpression of MAGL in non-aggressive cancer cells recapitulates this fatty acid network and increases their pathogenic phenotypes that are reversed by an MAGL inhibitor [56].

Recently, the orphan receptor G protein-coupled receptor 55 (GPR55) has been proposed as a potential cannabinoid receptor. Elevated GPR55 expression was showed in several ovarian cancer cell lines having a critical role in regulating proliferation. GPR55 mediates the effects of the endogenous ligand lysophosphatidylinositol (LPI), which activates Akt and calcium mobilization and extracellular signal-regulated kinase (ERK) 1/2 expression. Moreover, its down-regulation using small interfering RNA and pharmacological blockade strongly inhibits cell proliferation with important implication as a potential therapeutic target. [72].

Ovarian carcinoma cell-derived LPI stimulated angiogenesis in the chorioallantoic membrane (CAM) assay. Applied LPI stimulates proliferation, network formation and migration of neonatal endothelial colony-forming cells (ECFCs) in vitro and angiogenesis in the vivo. The pharmacological GPR55 inhibitor restrained LPI-stimulated ECFC proliferation, network formation and migration in vitro as well as ovarian carcinoma cell- and LPI-induced angiogenesis in vivo. [73].

Lately, a variable expression of the endocannabinoid system in human epithelial ovarian tumors was showed. The recorded data demonstrated that the expression of CB1R increased from benign and borderline to malignant ovarian tumors. [55].

All the recorded data give us hope that endocannabinoid system may be used in clinical practice, alone or in combination with other markers, to identify or better characterize ovarian tumors, without considering the great opportunity that they might represent as therapeutic targets.

\section{Conclusions}

Available data demonstrate that the endocannabinoid system may play a decisive role in the development and progression of gynaecological malignancy. Several different mechanisms have been implicated in the antitumor actions and include cytotoxic or cytostatic effects, apoptosis induction, and anti-metastatic effects such as the inhibition of neoangiogenesis, tumor cell migration, invasion, and adhesion. The endocannabinoid system activity is very complex, involving different signalling receptor and receptor-independent pathways. For this reason, further studies are needed to understand the exact role of the ECS and its complex activity. For sure the ECS represent an exciting challenge to researchers for its potential use in diagnosis and treatment of all gynaecological malignancies. 
Conceptualization, F.G. and E.M.M.; Methodology, R.A. and G.R.L.; Investigation, F.G. and B.Z.; Data Curation, F.G. B.Z.; Writing-Original Draft Preparation, F.G.; R.A.; G.R.L; C.P. ; Writing-Review \& Editing, C.P. E.M.M.; Supervision, E.M.M.

Funding: This research received no external funding

Acknowledgments: There are no acknowledgement.

Conflicts of Interest: The authors declare no conflict of interest. 


\section{References}

1. Iannotti, F.A.; Di Marzo, V.; Petrosino, S. Endocannabinoids and endocannabinoid related mediators: targets: metabolism and role in neurological disorders, Prog. Lipid, 2016 , Res. 62, 107-128.

2. Grotenhermen, F.; Pharmacology of endocannabinoids. Neuro Endocrinol Lett, 2004, 25 (1-2):14-23

3. Chiurchiu, V.; Battistini, L.; Maccarrone, M. ; Endocannabinoid signalling ininnate and adaptive immunity, Immunology, 2015, 144:352-64. doi:10.1111/imm.12.

4. Maccarrone, M.; Guzmán, M.; Mackie, K.; Doherty, P.; Harkany, T.; Programming emerging therapies, Nat Rev Neurosci, 2014, 15:786-801. doi:10.1038/nrn3846.

5. Devane, W.A.; Hanus, L.; Breuer, A.; Pertwee, R.G.; Stevenson, L.A.; et al. Isolation and structure of a brain constituent that binds to the cannabinoid receptor, Science, 1992, 258: 1946-1949.

6. Giang, D.K.; Cravatt, B.F. Molecular characterization of human and mouse fatty acid amide hydrolases, proceedings of the National Academy of Sciences of the United States of America, 1997, 94: 2238-2242.

7. Schuel, H. Tuning the oviduct to the anandamide tone, Journal of Clinical Investigation, 2006, 116: 2087-2090.

8. Matias, I.; Di Marzo, V. Endocannabinoid synthesis and degradation, and their regulation in the framework of energy balance, J. Endocrinol. Invest, 2006; 29 (3 Suppl):15-26.

9. Taylor, A.H.; Ang, C.; Bell, S.C.; Konje, J.C. The role of the endocannabinoid system in gametogenesis, implantation and early pregnancy, Human Reproduction, 2007, Update 13: 501-513.

10. Galiegue, S.; Mary, S.; Marchand, J.; Dussossoy, D.; Carriere, D.; et al. Expression of central and peripheral cannabinoid receptors in human immune tissues and leukocyte subpopulations, European Journal of Biochemistry, 1995, 232:54-61.

11. Kenney, S.P.; Kekuda, R.; Prasad, P.D.; Leibach, F.H.; Devoe, L.D.; et al. Cannabinoid receptors and their role in the regulation of the serotonin transporter in the human placenta, American Journal of Obstetrics and Gynecology, 1999, 181: 491-497. 
12. Parolaro, D.; Massi, P.; Rubino, T.; Monti, E. Endocannabinoids in the immune system and cancer, Prostaglandins Leukotrienes \& Essential Fatty Acids, 2002, 66: 319-332.

13. Habayeb, O.M.; Taylor, A.H.; Bell, S.C.; Taylor, D.J.; Konje, J.C. Expression of the endocannabinoid system in human first trimester placenta and its role in trophoblast proliferation, Endocrinology, 2008, 9: 5052-5060.

14. Godlewski, G.; Offertaler, L.; Wagner, J.A.; Kunos, G.; Receptors for acylethanolamides-GPR55 and GPR119, Prostaglandins Other Lipid Mediat, 2009, 89:105-111.

15. Qin, Y.; Verdegaal, E.M.; Siderius, M.; Bebelman, J.P.; Smit, M.J.; Leurs, R.; Willemze, R.; Tensen, C.P.; Osanto, S. Quantitative expression profiling of G-protein-coupled receptors (GPCRs) in metastatic melanoma: the constitutively active orphan GPCR GPR18 as novel drug target, Pigment Cell Melanoma Res, 2011, 24:207-218.

16. Okuno, T.; Yokomizo, T. What is the natural ligand of GPR55?, J Biochem,2011 , 149:495-497.

17. Perez-Gomez, E.; Andradas, C.; Flores, J.M.; Quintanilla, M.; Paramio, J.M.; Guzman, M.; Sanchez, C. The orphan receptor GPR55 drives skin carcinogenesis and is upregulated in human squamous cell carcinomas, Oncogene, 2013, 32:2534-2542.

18. HHuang, S.M.; Bisogno, T.; Trevisani, M.; Al-Hayani, A.; De Petrocellis, L.; Fezza, F.; Tognetto, M.; Petros, T.J.; Krey, J.F.; Chu, C.J.; et al. An endogenous capsaicin-like substance with high potency at recombinant and native vanilloid VR1 receptors, Proc Natl Acad Sci USA, 2002, 99:8400-8405.

19. Pistis, M.; Melis, M.; From surface to nuclear receptors: the endocannabinoid family extends its assets, Curr Med Chem, 2010, 17:1450-1467.

20. Merroun, I.; Sanchez-Gonzalez, C.; Martinez, R.; Lopez-Chaves, C.; Porres, J.M.; Aranda, P.; Llopis, J.; Galisteo, M.; Zarzuelo, A.; Errami, M. Novel effects of the cannabinoid inverse agonist AM 251 on parameters related to metabolic syndrome in obese Zucker rats, Metabolism, 2013, 62:1641-1650.

21. De Petrocellis, L.; Orlando, P.; Moriello, A.S.; Aviello, G.; Stott, C.; Izzo, A.A.; Di Marzo, V. Cannabinoid actions at TRPV channels: effects on TRPV3 and TRPV4 and their potential relevance to gastrointestinal inflammation, Acta Physiol (Oxf), 2012, 204:255-266.

22. Borrelli, F.; Fasolino, I.; Romano, B.; Capasso, R.; Maiello, F.; Coppola, D.; Orlando, P.; Battista, G.; Pagano, E.; Di Marzo, V.; et al. Beneficial effect of the non-psychotropic plant cannabinoid cannabigerol on experimental inflammatory bowel disease, Biochem Pharmacol, 2013, 85:1306-1316. 
23. Liu, Y.J.; Fan, H.B.; Jin, Y.; Ren, C.G.; Jia, X.E.; Wang, L.; Chen, Y.; Dong, M.; Zhu, K.Y.; Dong, Z.W.; et al. Cannabinoid receptor 2 suppresses leukocyte inflammatory migration by modulating the JNK/c-Jun/Alox5 pathway, J Biol Chem, 2013, 288:13551-13562.

24. Disis, M.L. Immune regulation of cancer, 2010, J Clin Oncol,28:4531-4538.

25. Walker, J.M.; Huang, S.M. Endocannabinoids in pain modulation, Prostaglandins Leukot Essent Fatty Acids, 2002, 66:235-242

26. Johnson, J.R.; Burnell-Nugent, M.; Lossignol, D.; Ganae-Motan, E.D.; Potts, R.; Fallon, M.T. Multicenter, double-blind, randomized, placebo-controlled, parallel-group study of the efficacy, safety, and tolerability of THC: CBD extract and THC extract in patients with intractable cancer-related pain, 2010, J Pain Symptom Manage, 2010;39:167-179.

27. Gu, X.; Mei, F.; Liu,Y.; Zhang, R.; Zhang, J.; Ma, Z. Intrathecal administration of the cannabinoid 2 receptor agonist JWH015 can attenuate cancer pain and decrease mRNA expression of the $2 \mathrm{~B}$ subunit of N-methyl-D-aspartic acid, Anesth Analg, 2011, 113:405-411.

28. Pisanti, S.; Borselli,C.; Oliviero, O.; Laezza, C.; Gazzerro, P.; Bifulco, M. Antiangiogenic activity of the endocannabinoid anandamide: correlation to its tumor-suppressor efficacy, J Cell Physiol, 2007, 211:495-503

29. Hanahan, D.; Weinberg, R.A. Hallmarks of cancer: the next generation, Cell, 2011, 144:646-674.

30. Velasco, G.; Sanchez, C.; Guzman, M. Towards the use of cannabinoids as antitumour agents, Nat Rev Cancer, 2012, 12:436-444.

31. Pisanti, S.; Picardi, P.; D’Alessandro, A.; Laezza,C.; Bifulco , M. The endocannabinoid signaling system in cancer, Trends Pharmacol Sci, 2013, 34:273-282.

32. Van Dross, R.; Soliman, E.; Jha, S.; Johnson, T.; Mukhopadhyay, S. Receptor-dependent and receptor-independent endocannabinoid signaling: a therapeutic target for regulation of cancer growth, Life Sci, 2013, 92:463-466.

33. Ayakannu, T.; Taylor, A.H.; Marczylo, T.H.; Willets, J.M.; Konje, J.C. The endocannabinoid system and sex steroid hormone-dependent cancers, Int J Endocrino, 2013:259676, doi: 10.1155/2013/259676

34. Meccariello, R.; Battista, N.; Bradshaw, H.B.; Wang, H. Endocannabinoids and reproduction, Int J Endocrinol, 2014:378069

35. Fonseca,B.M.; Teixeira, N.A.; Correia-da-Silva, G, Cannabinoids as Modulators of Cell Death: Clinical Applications and Future Directions, Rev Physiol Biochem Pharmacol. 7, 2017, DOI 10.1007/112_2017_3z 
36. Kim, S.R.; Lee, D.Y.; Chung, E.S.; Oh, U.T.; Kim, S.U.; Jin, B.K. Transient receptor potential vanilloid subtype 1 mediates cell death of mesencephalic dopaminergic neurons in vivo and in vitro, J Neurosci. Jan, 2005, 19;25(3):662-71.

37. Maccarrone, M.; Lorenzon, T.; Bari, M.; Melino, G.; Finazzi-Agro, A. Anandamide induces apoptosis in human cells via vanilloid receptors. Evidence for a protective role of cannabinoid receptors, J Biol Chem, 2000, 275:31938-31945.

38. Costa, M.A.; Fonseca, B.M.; Keating, E.; Teixeira, N.A.; Correia-da-Silva, G. 2-arachidonoylglycerol effects in cytotrophoblasts: metabolic enzymes expression and apoptosis in BeWo cells, Reproduction, 2014, 3;147(3):301-11, doi: 10.1530/REP-13-0563

39. Athanasiou, A.; Clarke, A.B.; Turner, A.E.; Kumaran, N.M.; Vakilpour, S.; Smith, P.A.; Bagiokou, D.; Bradshaw, T.D.; Westwell, A.D.; Fang, L. et al. Cannabinoid receptor agonists are mitochondrial inhibitors: a unified hypothesis of how cannabinoids modulate mitochondrial function and induce cell death, Biochem Biophys Res Commun, 2007, 364:131-137.

40. Curran, S.; Murray, G.I. Matrix metalloproteinases: molecular aspects of their roles in tumour invasion and metastasis, Eur J Cancer, 2000, 36(13 Spec. No.):1621-1630.

41. Blazquez, C.; Salazar, M.; Carracedo, A.; Lorente, M.; Egia, A.; Gonzalez-Feria, L.; Haro, A.; Velasco, G.; Guzman, M. Cannabinoids inhibit glioma cell invasion by down-regulating matrix metalloproteinase-2 expression, Cancer Res, 2008, 68:1945-1952.

42. Freimuth, N.; Ramer, R.; Hinz, B. Antitumorigenic effects of cannabinoids beyond apoptosis, J Pharmacol Exp Ther, 2010, 332:336-344.

43. Portella, G.; Laezza, C.; Laccetti, P.; De Petrocellis, L.; Di Marzo, V.; Bifulco, M. Inhibitory effects of cannabinoid CB1 receptor stimulation on tumor growth and metastatic spreading: actions on signals involved in angiogenesis and metastasis, FASEB J, 2003, 17:1771-1773.

44. Blazquez, C.; Gonzalez-Feria, L.; Alvarez, L.; Haro, A.; Casanova, M.L.; Guzman, M. Cannabinoids inhibit the vascular endothelial growth factor pathway in gliomas, Cancer Res, 2004, 64:5617-5623.

45. El-Talatini, M.R.; Taylor, A.H.; Elson, J.C.; Brown, L.; Davidson, A.C.; Konje, J.C. Localisation and function of the endocannabinoid system in the human ovary, PLoS One, 2009, 4: e4579; 
46. Schuel,H.; Burkman, L.J.; Lippes, J.; Crickard, K.; Forester, E.; Piomelli, D.; Giuffrida, A. N-Acylethanolamines in human reproductive fluids, Chem Phys Lipids, 2002, 121:211-227;

47. Adashi, E.Y.; Jones, P.B.; Hsueh, A.J. Direct antigonadal activity of cannabinoids: suppression of rat granulosa cell functions, Am J Physiol, 1983, 244: E177-E185;

48. Gebeh, A.; Willets, J.M.; Marczylo, E.; Taylor, A.H.; Konje, J.C. Ectopic pregnancy is associated with high anandamide levels and aberrant expression of FAAH and CB1 in Fallopian tubes, J Clin Endocrinol Metab, 2012, 97:2827-2835;

49. Wang, H.; Guo, Y.; Wang, D.; Kingsley, P.J.; Marnett, L.J.; Das, S.K.; DuBois, R.N.; Dey, S.K. Aberrant cannabinoid signaling impairs oviductal transport of embryos, Nat Med, 2004, 10:1074-1080.

50. Horne, A.W.; Philips, J.A.3 ${ }^{\text {rd }}$, KaneNet, al. CB1 expression is attenuated in Fallopian tube and decidua of women with ectopic pregnancy, PLoS One, 2008, 3: e3969;

51. Taylor, A.H.; Abbas, M.S.; Habiba, M.A.; Konje, J.C. Histomorphometric evaluation of cannabinoid receptor and anandamide modulating enzyme expression in thehuman endometrium through the menstrual cycle, Histochem Cell Biol, 2010, 133:557-565.

52. Resuehr, D.; Glore, D.R.; Taylor, H.S.; Bruner-Tran, K.L.; Osteen, K.G. Progesterone-dependent regulation of endometrial cannabinoid receptor type 1 (CB1-R) expression is disrupted in women with endometriosis and in isolated stromal cells exposed to 2,3,7,8-tetrachlorodibenzo-p-dioxin (TCDD), Fertil Steril, 2012, 98:948-956 e941.

53. Fonseca, B.M.; Correia-da-Silva, G.; Taylor, A.H.; Lam, P.M.; Marczylo, T.H.; Konje, J.C. N-acylethanolamine levels and expression of their metabolizing enzymes during pregnancy, Endocrinology, 2010, 151:396-3974.

54. Ayakannu, T.; Taylor, A.H.; Willets, J.M.; Konje, J.C. The evolving role of the endocannabinoid system in gynaecological cancer, Hum Reprod Update, 2015. 21:517-35;

55. Messalli, E.M.; Grauso, F.; Luise, R.; Angelini, A.; Rossiello, R. Cannabinoid receptor type 1 immunoreactivity and disease severity in human epithelial ovarian tumors, Am J Obstet Gynecol, 2014, 211: 234.e1-6;

56. Nomura, D.K.; Long, J.Z.; Niessen, S.; Hoover, H.S., N.g., S.W.; Cravatt, B.F. Monoacylglycerol lipase regulates a fatty acid network that promotes cancer pathogenesis, Cell, 2010, 140:49-61; 
57. Paria, B.C.; Song, H.; Wang, X.; Schmid, P.C.; Krebsbach, R.J.; Schmid, H.H.; Bonner, T.I.; Zimmer, A.; Dey, S.K. Dysregulated cannabinoid signaling disrupts uterine receptivity for embryo implantation, J Biol Chem, 2001, 276:20523-20528.

58. El-Talatini, M.R.; Taylor, A.H.; Konje, J.C. The pattern of anandamide expression throughout the menstrual cycle and its hormonal modulation, Fertil. Steril, 2010, 93:1989-1996.

59. Guida, M.; Ligresti, A.; De Filippis, D.; D’Amico, A.; Petrosino, S.; Cipriano, M.; Bifulco, G.; Simonetti, S.; Orlando, P.; Insabato, L. et al. The levels of the endocannabinoid receptor CB2 and its ligand 2-arachidonoylglycerol are elevated in endometrial carcinoma, Endocrinology, 2010, 151:921-928.

60. Schmid, P.C.; Wold, L.E.; Krebsbach, R.J.; Berdyshev, E.V.; Schmid, H.H. Anandamide and other N-acylethanolamines in human tumors, Lipids, 2002, 37:907-912.

61. Guzman, M.; Sanchez, C.; Galve-Roperh, I. Cannabinoids and cell fate, Pharmacol Ther, 2002, 95:175-184.

62. Patel, S.; Ahmed, S. Emerging Field of Metabolomics: Big Promise for Cancer Biomarker Identification and Drug Discovery, J Pharm Biomed Anal. 2014, 107: 63-74. doi: 10.1016/j.jpba.2014.12.020.

63. Johnson, C.H.; Dejea, C.M.; Edler, D.; Hoang, L.T.; Santidrian, A.F.; Felding, B.H.; Ivanisevic, J.; Cho, K.; Wick, E.C.; Hechenbleikner, E.M.; Uritboonthai, W.; Goetz, L.; Casero, R.A.; et al. Metabolism Links Bacterial Biofilms and Colon Carcinogenesis, Cell Metab. 2015, 21: 891-7. doi: 10.1016/j.cmet.2015.04.011.

64. Zhang, A.; Sun, H.; Yan, G.; Wang, P.; Han, Y.; Wang, X. Metabolomics in diagnosis and biomarker discovery of colorectal cancer, Cancer Lett. 2014, 345: 17-20. doi: 10.1016/j.canlet.2013.11.011

65. Jové M.; Gatius $_{\llcorner}$S.; Yeramian, A.; Portero-Otin M.; Eritja $_{\llcorner}$N.; Santacana $_{\llcorner}$M.; Colas $_{\llcorner}$E.; Ruiz ${ }_{\llcorner}$M.; Pamplona, R.; Matias-Guiu, X. Metabotyping human endometrioid endometrial adenocarcinoma reveals an implication of endocannabinoid metabolism, Oncotarget, 2016, 9;7(32):52364-52374. doi: 10.18632/oncotarget.10564.

66. Dobovišek ${ }_{L}$ L.; Hojnik ${ }_{L}$ M.; Ferk ${ }_{L}$ P. Overlapping molecular pathways between cannabinoid receptors type 1 and 2 and estrogens/androgens on the periphery and their involvement in the pathogenesis of common diseases (Review), Int J Mol Med. 2016, 38(6):1642-1651. doi: 10.3892/ijmm.2016.2779

67. Fonseca, B.M.; Correia-da-Silva, G.; Teixeira, N.A. Cannabinoid-induced cell death in endometrial cancer cells: involvement of TRPV1 receptors in 
apoptosis, J Physiol Biochem, 2018, 74(2):261-272. doi: 10.1007/s13105-018-0611-7.

68. Contassot, E.; Tenan, M.; Schnuriger, V.; Pelte, M.F.; Dietrich, P.Y. Arachidonyl ethanolamide induces apoptosis of uterine cervix cancer cells via aberrantly expressed vanilloid receptor-1, Gynecol Oncol 2004, 93:182-188.

69. Eichele, K.; Ramer, R.; Hinz, B. R(+)-methanandamide-induced apoptosis of human cervical carcinoma cells involves a cyclooxygenase-2-dependent pathway, Pharm Res, 2009, 26:346-355.

70. Ramer, R.; Hinz, B. Inhibition of cancer cell invasion by cannabinoids via increased expression of tissue inhibitor of matrix metalloproteinases-1, J Natl Cancer Inst, 2008, 100:59-69.

71. Bagavandoss, P.; Grimshaw, S. Temporal and spatial distribution of the cannabinoid receptors (CB1, CB2) and fatty acid amide hydroxylase in the rat ovary, Anat Rec (Hoboken), 2010, 293:1425-32;

72. Piñeiro,R.; Maffucci, T.; Falasca, M. The putative cannabinoid receptor GPR55 defines a novel autocrine loop in cancer cell proliferation, Oncogene, 2011, 13;30(2):142-52. doi: 10.1038/onc.2010.417.

73. Hofmann, N.A.; Yang, J.; Trauger, S.A.; et al. The GPR 55 agonist, L- $\alpha$-lysophosphatidylinositol, mediates ovarian carcinoma cell-induced angiogenesis, Br J Pharmacol, 2015, 172:4107-18; 